\title{
Cost-effectiveness of positive airway pressure modalities in obesity hypoventilation syndrome with severe obstructive sleep apnoea
}

\author{
Juan F Masa (D) , 1,2,3 Babak Mokhlesi (D) ," Iván Benítez (D) , 2,5 \\ Francisco Javier Gómez de Terreros Caro (D) ,,2,3 M-Ángeles Sánchez-Quiroga (D) , 2,3,6 \\ Auxiliadora Romero (D) ,', Candela Caballero (D) ,', Maria Luz Alonso-Álvarez (1) ,,8 \\ Estrella Ordax-Carbajo (D) , 2,8 Teresa Gómez-García (D) , 2,9 Mónica González (D) , 10 ' \\ Soledad López-Martín (1) ,' Jose M Marin (D) , 2,12 Sergi Martí (1) , 2,13 \\ Trinidad Díaz-Cambriles (D) , ${ }^{2,14}$ Eusebi Chiner (D) , ${ }^{15}$ Carlos Egea (D) , ${ }^{11,16}$ \\ Javier Barca (D) , 3,17 Francisco-José Vázquez-Polo (D) , ${ }^{18}$ Miguel Angel Negrín (D) , 18 \\ María Martel-Escobar (D) , ${ }^{18}$ Ferran Barbé (D) , ${ }^{2,5}$ Jaime Corral-Peñafiel (D) , ${ }^{1,2,3}$ on \\ behalf of the Spanish Sleep Network
}

- Additional material is published online only. To view please visit the journal online (http://dx.doi.org/10.1136/ thoraxinl-2019-213622).

For numbered affiliations see end of article.

\section{Correspondence to} Dr Juan F Masa, San Pedro de Alcantara Hosopital, Caceres, Spain and Ciber de Enfermedades Respiratorias (CIBERES), Caceres 10005, Spain; fmasa@separ.es

Received 27 May 2019 Revised 16 October 2019 Accepted 25 November 2019 Published Online First 26 March 2020

\section{Linked}

- http://dx.doi.org/10.1136/ thoraxjnl-2019-214403

Check for updates

(C) Author(s) (or their employer(s)) 2020. No commercial re-use. See rights and permissions. Published by BMJ.

To cite: Masa JF, Mokhlesi B, Benítez I, et al. Thorax 2020;75:459-467

\section{ABSTRACT \\ Background Obesity hypoventilation syndrome \\ $(\mathrm{OHS})$ is treated with either non-invasive ventilation \\ (NIV) or CPAP, but there are no long-term cost- \\ effectiveness studies comparing the two treatment \\ modalities.}

Objectives We performed a large, multicentre, randomised, open-label controlled study to determine the comparative long-term cost and effectiveness of NIV versus CPAP in patients with OHS with severe obstructive sleep apnoea (OSA) using hospitalisation days as the primary outcome measure.

Methods Hospital resource utilisation and within trial costs were evaluated against the difference in effectiveness based on the primary outcome (hospitalisation days/year, transformed and nontransformed in monetary term). Costs and effectiveness were estimated from a log-normal distribution using a Bayesian approach. A secondary analysis by adherence subgroups was performed.

Results In total, 363 patients were selected, 215 were randomised and 202 were available for the analysis. The median (IQR) follow-up was 3.01 (2.913.14) years for NIV group and 3.00 (2.92-3.17) years for CPAP. The mean (SD) Bayesian estimated hospital days was 2.13 (0.73) for CPAP and $1.89(0.78)$ for NIV. The mean (SD) Bayesian estimated cost per patient/ year in the NIV arm, excluding hospitalisation costs, was $€ 2075.98$ (91.6), which was higher than the cost in the CPAP arm of $€ 1219.06$ (52.3); mean difference $€ 857.6$ (105.5). CPAP was more cost-effective than NIV (99.5\% probability) because longer hospital stay in the CPAP arm was compensated for by its lower costs. Similar findings were observed in the high and low adherence subgroups.

Conclusion CPAP is more cost-effective than NIV; therefore, CPAP should be the preferred treatment for patients with OHS with severe OSA.

Trial registration number NCT01405976

\section{Key messages}

What is the key question?

- No studies have assessed the cost-effectiveness of non-invasive ventilation (NIV) versus CPAP in patients with obesity hypoventilation syndrome (OHS) and severe obstructive sleep apnoea (OSA).

What is the bottom line?

- Both NIV and CPAP improve clinical symptoms, polysomnographic parameters, daytime $\mathrm{PaCO}_{2}$ and hospital resource utilisation in patients with OHS and severe OSA. However, CPAP is simpler to implement and is less costly than NIV.

Why read on?

- This is the first randomised controlled trial that evaluates the cost-effectiveness relationship between CPAP and NIV showing that CPAP is more cost-effective than NIV; therefore, CPAP should be the first-line treatment for stable ambulatory patients with OHS with severe OSA.

\section{INTRODUCTION}

Obesity hypoventilation syndrome (OHS) is characterised by obesity and chronic hypercapnic respiratory failure that is not secondary to other causes. ${ }^{1}$ Around $90 \%$ of patients with OHS have related obstructive sleep apnoea (OSA), ${ }^{2}$ with $73 \%$ having severe OSA. ${ }^{3}$

Cardiovascular morbidity is more prevalent in patients with OHS than in patients with eucapnic $\mathrm{OSA}^{45}$ or in eucapnic obesity, ${ }^{67}$ leading to increased healthcare-related costs. ${ }^{7}$ Moreover, patients with untreated OHS are at increased risk of hospitalisation and death, ${ }^{6-11}$ likely because of respiratory complications. ${ }^{12-14}$ 
OHS is treated with positive airway pressure (PAP) therapy during sleep. The two most common modes of PAP therapy are non-invasive ventilation (NIV) and CPAP. The effectiveness of NIV has been assessed in several long-term, observational studies ${ }^{4-8}$ 15-21 and medium-term randomised trials. ${ }^{322} 23$ CPAP prevents upper airway obstructive events although, theoretically, it is not the treatment of choice for non-obstructive sleep hypoventilation. ${ }^{19}$ Several medium-term ${ }^{324} 25$ and one longterm $^{26}$ randomised clinical trial have reported similar effectiveness between NIV and CPAP.

CPAP is simpler to implement and is less costly than NIV. ${ }^{26}$ However, there are no studies that have specifically investigated which of the two treatments is more cost-effective. To that end, we carried out a post hoc, within-trial, cost-effectiveness analysis using a large multicentre, open-labelled, randomised controlled study (Pickwick study). ${ }^{3}{ }^{23}{ }^{26-30}$ We aimed to determine the comparative cost-effectiveness relationship between NIV and CPAP based on 3 years of follow-up, using hospitalisation days as the primary outcome measure in a cost-effectiveness analysis, or considering the hospitalisation days in monetary term where the value of a hospitalisation day is approximate for its cost, in a cost-benefit analysis.

\section{METHODS}

\section{Trial design}

We carried out a multicentre, open-label, randomised clinical trial with two parallel groups conducted at 16 clinical sites in Spain. There were no changes in the protocol after trial commencement.

\section{Participants}

From May 2009 to March 2013, we sequentially screened patients between 15 and 80 years of age who were referred for pulmonary consultation due to suspected OHS or OSA at 16 tertiary care hospitals in Spain (see online supplement). OHS was defined as obesity, with a body mass index (BMI) $\geq 30 \mathrm{~kg} /$ $\mathrm{m}^{2}$, stable hypercapnic respiratory failure $\left(\mathrm{PaCO}_{2} \geq 45 \mathrm{~mm} \mathrm{Hg}\right.$, $\mathrm{pH} \geq 7.35$, no clinical worsening during the two previous months), no relevant COPD $\left(\mathrm{FEV}_{1}>70 \%\right.$ of predicted when $\mathrm{FEV}_{1}$ :FVC <70), without neuromuscular, chest wall or metabolic disease. Other inclusion criteria were as follows: (1) severe OSA (apnoea-hypopnoea index (AHI) $\geq 30$ ); (2) an absence of narcolepsy or restless leg syndrome; (3) a correctly executed 30 min PAP (CPAP/NIV) treatment test (see online supplement). The exclusion criteria were as follows: (1) a psychophysical inability to complete questionnaires; (2) severe chronic debilitating illness; (3) severe chronic nasal obstruction; (4) a lack of informed consent.

The Pickwick project consisted of two parallel randomised controlled trials conducted over two phases (online supplementary figure S1).

\section{Interventions}

Stable ambulatory patients with OHS and concomitant severe OSA (AHI $\geq 30$ ) were randomised by an electronic database (simple randomisation without predetermined allocation rate) into NIV, CPAP or control group for the first 2 months (first phase). After this period, due to pre-specified ethical reasons, patients included in the control group (ie, lifestyle changes) were re-randomised to NIV or CPAP by a simple randomisation. Patients randomised to NIV or CPAP were followed for 3 years (second phase).
All patients, including those in the CPAP and NIV arms, were instructed on lifestyle modification (see online supplement). Oxygen therapy was added if baseline daytime or nocturnal hypoxemia during PAP adjustment was detected. ${ }^{30}$

\section{Continuous positive airway pressure}

Patients were instructed on how to use CPAP at a fixed pressure at home during the entire sleep period. The CPAP setting was determined based on a conventional CPAP titration study (see online supplement).

\section{Non-invasive ventilation}

Patients were instructed to use NIV treatment during the entire sleep period. The ventilator mode was set at a bi-level PAP with assured volume (see online supplement).

\section{Masking strategy}

The study was open label for both investigators and patients. Clinicians from the treating teams (routine care team), however, were unaware of the research study (see online supplement).

\section{Follow-up and outcomes}

Patients were evaluated on 12 occasions during 3 years: at baseline, after the first and second months, and every 3 months until completing 2 years, then every 6 months until completing 3 years of follow-up (see online supplementary table S1 and more details in the online supplement). Evaluations at months 1 and 2 were performed before the re-randomisation of the control group to CPAP or $\mathrm{NIV}^{3}$ (figure 1). Consequently, these controls were not included in the 1-month and 2-month analyses.

During every visit after baseline 1, we assessed the primary outcome (hospitalisation days for any cause) and secondary outcomes such as hospital resource utilisation (admissions to the hospital, ICU and emergency department visits) and all-cause mortality. Mortality was ascertained from the medical records in the official electronic health system database and from the patient's family. Patients also underwent arterial blood gas (ABG) on room air (see online supplement), sphygmomanometric blood pressure ${ }^{31}$ (see online supplement), spirometry, ${ }^{32} 6 \mathrm{~min}$ walk distance (6-MWD) test ${ }^{33}$ and health-related quality of life (HRQL) tests using the Functional Outcomes of Sleep Questionnaire (FOSQ), the Medical Outcome Survey Short Form 36 (SF36) and the visual analogical well-being scale (VAWS). ${ }^{34} 35$ In the first, second and third annual visits, we assessed the incidence of new cardiovascular events including new diagnosis of hypertension (or initiation of antihypertensive treatment), atrial fibrillation, hospitalisations for non-fatal myocardial infarction or unstable angina, non-fatal stroke or transient ischaemic attack, heart failure episode and cardiovascular death. This information was obtained the same way as hospitalisation days. At each annual visit, we confirmed CPAP/NIV settings and measured adherence to CPAP/NIV using internal device hourly counters.

\section{Statistical analysis}

Sample size was calculated to detect differences in the primary outcome variable, assuming an alpha error of 0.05 and a beta error of 0.2 . At the time of study design, the mean hospital stay in patients receiving chronic NIV was $2.5 \pm 1$.1 days/patientyear. ${ }^{7}$ We estimated that an intergroup mean difference of $\geq 0.5$ (SD 1.1) days/patient-year (20\% difference) could be clinically relevant. We estimated a sample size of at least 77 patients in each group. No missing data imputation was carried out. 


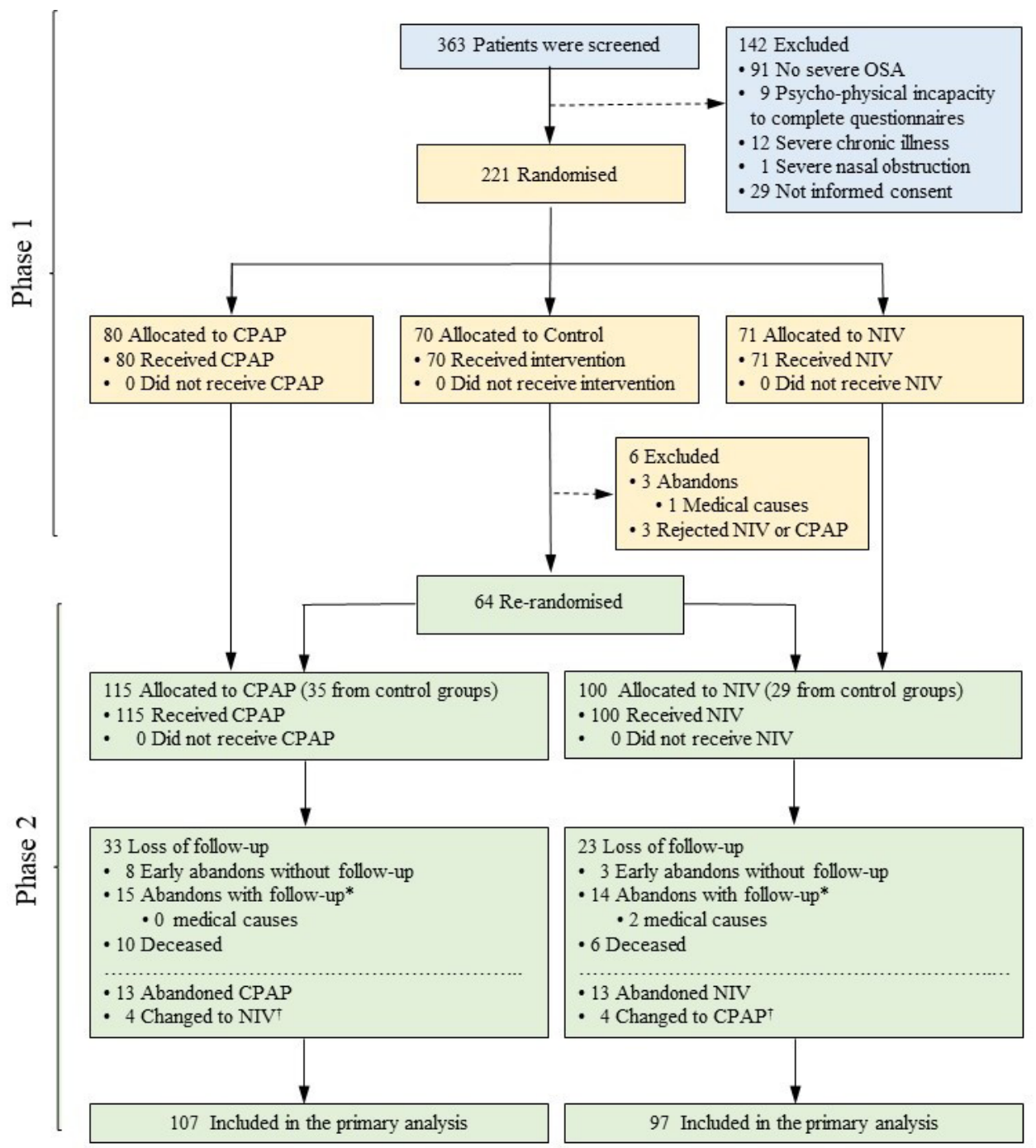

Figure 1 Flow chart of the study protocol. of 363 selected patients, 142 were excluded and 221 were randomised. After the first 2 months of treatment (first phase), patients included in the control group (ie, lifestyle changes) were re-randomised to CPAP or non-invasive ventilation (NIV) in order to be followed for a minimum of 3 years (second phase). 215 patients were randomised to either CPAP ( $n=115)$ or NIV ( $n=100)$. From the 115 patients included in the CPAP arm, 8 abandoned the study early without follow-up and the rest $(n=107)$ were available for the primary analysis. From the 100 patients included in the NIV arm, 3 abandoned the study early without follow-up and the rest ( $n=97)$ were available for the primary analysis. *Participants who at some point were lost to follow-up but did not withdraw informed consent were followed to the end of the study in order to obtain data on hospital resource utilisation (including the primary outcome of hospitalisation days), treatment type and mortality. ${ }^{\dagger}$ Patients who changed treatment after randomisation (ie, from CPAP to NIV or vice versa) were analysed in the original arm according to the intention-to-treat principle. OSA, obstructive sleep apnoea.

\section{Cost-effectiveness analysis}

The within-trial cost of the two arms was evaluated during the 3 years of the study. We analysed the following cost groups based on the 2018 value of the Euro $(€)$ :

1. Primary outcome cost: The cost of hospitalisation days reported by each centre.

2. Other hospital resource cost: The cost of ICU days and emergency department visits reported by each centre.

3. The cost of short visits (non-annual visits) and long visits (baseline and annual visits): For these visits, $90 \%$ of the time was allocated to the nurses and $10 \%$ to the research physician in both arms. We also estimated the proportional burden of the consultation space on the general budget of each hospital. The duration of the visits was estimated based on the average of time spent at three centres. The cost of the personnel (ie, nurse and physician) was calculated taking into account the staff salaries at each centre.
4. The cost of baseline daytime adjustment of NIV and associated tests included the time spent by the research physician in this task and the proportional burden of the consultation space on the general budget of each hospital. The time was estimated based on the average time spent at three centres.

a. ABG, spirometry and 6-MWD test costs included the time spent by the nurses, linear 5 -year depreciation of equipment (considering the estimated number of recordings conducted in this period in each hospital), consumables and the proportional burden of the Pulmonary Function Laboratory on the general budget of the hospital. The time for these tasks was stipulated by each centre. The time for the nurses was calculated taking into account the nurses' salaries at each centre.

b. Polysomnographies (baseline and titration): Test costs included time spent by personnel (technicians, physicians and secretaries), linear 5-year depreciation of equipment 
(considering the number of recordings conducted in this period in each hospital), consumables and the proportional burden of the sleep laboratory on the general budget of the hospital. The technician cost of the polysomnography titration for CPAP was considered at half of the polysomnography technician cost for NIV because in our environment, a sleep technician attends two beds for CPAP titration but only one for a more complex NIV titration.

c. Blood pressure cost included the time spent by nurses, linear 5 -year depreciation of equipment (considering the estimated number of recordings conducted in this period in each hospital), consumables and the proportional burden of the consultation space on the general budget of the hospital. The time was the stipulated at each centre for this task. The cost of time was calculated taking into account the nurses' salaries at each centre.

5. Medication cost: Because the cost of medications depends to a great extent on the comorbidities, we made assumptions based on recommendations of the correspondent clinical practice guidelines. For hypertension, we allocated a cost based on the number of drugs at baseline visit and the rest of the visits. For type 2 diabetes and dyslipidaemia, we allocated an average cost if the patient was on treatment or not at baseline and during the rest of the visits. For the rest of the comorbidities (stroke, ischaemic heart disease, atrial fibrillation, peripheral arteriopathy and heart failure), an average cost was applied at baseline and in each of the visits depending if a new event appeared (see online supplementary table S2).

6. Home care costs: Supplemental oxygen and CPAP/NIV costs were the monetary cost that each centre payed per patient to its home care provider. These costs included the time spent by personnel (technicians, nurses and secretaries), home visits, linear 5 -year depreciation of equipment and consumables.

For the analysis, cost/patient was obtained dividing the cost by the years of follow-up. The comparison between the two arms was performed using two different approaches: (a) the primary outcome (hospitalisation days/year) was transformed to monetary term (see below) using the cost of hospitalisation days/year at each centre. This cost is compared with the rest of costs to determine the less expensive treatment; and (b) a conventional cost-effectiveness analysis where the effectiveness was assessed directly as hospitalisation days/year. In this analysis, the final decision will depend on how much the decision-maker is willing to pay for reducing hospitalisation days. This analysis is useful as a sensitivity analysis on what treatment is preferred for different willingness to pay for a day of hospitalisation. For both analyses, we adopted a probabilistic Bayesian approach, ${ }^{36}$ where the parameters of interest are treated as random variables, and reports evidence in a probabilistic manner. Bayesian inference computes the posterior probability according to Bayes' theorem combining the prior distribution with the likelihood of the data. We performed an objective Bayesian analysis where non-informative proper priors were assumed (see online supplement). ${ }^{37}$

A secondary cost-effectiveness was also carried out considering HRQL variables, in particular FOSQ, as measure of effectiveness (see online supplement). FOSQ presented a high proportion of missing data (28\%), so the conclusions of this analysis should be interpreted with caution. The effect on the cost-effectiveness analysis of a higher proportion of early abandons in the CPAP group was studied through a sensitivity analysis in three scenarios (see online supplement).

\section{Effectiveness assessed in monetary term}

Because a large number of patients were not hospitalised during the study follow-up, we performed a hurdle model, which first estimated the probability of being admitted (according to the Bernoulli distribution) and, later, the average cost of hospitalisation of those who were hospitalised. ${ }^{38}$ Due to the asymmetry of the cost distribution, a log-normal distribution was used. The average hospitalisation cost was estimated by the product of the probability of being hospitalised and the average costs of those who were hospitalised. The remainder of cost was calculated from the sum of costs in the different groups. A log-normal distribution was also used and the correlation between effectiveness and cost was taken into account through multivariate lognormal distribution. The cost-effectiveness plane illustrates the joint distribution of the incremental effectiveness in monetary term (savings from hospitalisation cost) and other incremental costs in an $\mathrm{x}-\mathrm{y}$ plot.

\section{Effectiveness assessed as hospitalisation days/year}

The hurdle model for effectiveness and cost was similar to the previous approach but the effectiveness was assessed as hospitalisation days/year. We also assumed a log-normal distribution for the effectiveness. In addition to the cost-effectiveness plane, we calculated the cost-effectiveness acceptability curve in which the probability of preference for one of the two treatments is displayed as a function of the willingness to pay for one point on the reduction in hospitalisation days/year.

\section{Adherence subgroups}

The same analysis with the two approaches of cost-effectiveness relationship was repeated according to adherence subgroups. Adherence to CPAP or NIV was categorised in two groups using the lowest tertile of mean daily use ( $\leq 4$ hours per day) as low adherence versus the highest two tertiles ( $>4$ hours per day) as high adherence. ${ }^{26}$ Data management and statistical analyses were performed using SPSS V.22.0, Stata software (Stata Statistical Software: Release 13; College Station, TX: StataCorp LP) and OpenBUGS software (OpenBUGS, V.3; Free Software Foundation).

\section{RESULTS}

\section{Study participants}

Of the 363 patients who met inclusion criteria, 142 were excluded (91 had AHI <30). In the second phase, 100 patients were randomised to NIV and 115 to CPAP (figure 1), and 97 patients in the NIV arm and 107 in the CPAP arm were available for the cost-effectiveness analysis. Table 1 summarises baseline characteristics of the two groups. There were no significant differences in baseline characteristics. The median (IQR) follow-up was 3.00 (2.92-3.17) years for CPAP and 3.01 (2.91-3.14) years for NIV group. The median (IQR) treatment adherence for CPAP was 6.0 (3.00-7.00) hours/day. The median (IQR) treatment adherence for NIV was 6.0 (1.29-7.24) hours/day (online supplementary figure S2).

Online supplementary figure $\mathrm{S} 3$ shows the histogram of hospitalisation days/year and its $\log$ transformation for the non-zero values. Online supplementary figure $S 4$ shows hospitalisation costs. Online supplementary figure S5 shows these histograms but for other costs. The average stay of patients in the CPAP arm was slightly, although not significantly, higher in the CPAP group (in $35.5 \%$ who required hospital admission, the average stay was 5.2 days/year) than in NIV group (in $35.1 \%$ who required hospital admission, the average stay was 4.7 days/year) (table 2). The subsequent hospitalisation days cost/year was also higher in 
Table 1 Baseline characteristics*

\begin{tabular}{|c|c|c|c|}
\hline & $\begin{array}{l}\text { CPAP } \\
n=107 \\
n(\%) \text { or mean (SD) or } \\
\text { median }(25 ; 75 \text { IQR) }\end{array}$ & $\begin{array}{l}\text { NIV } \\
n=97 \\
n(\%) \text { or mean (SD) or } \\
\text { median }(25 ; 75 \text { IQR) }\end{array}$ & P valuet \\
\hline Age, years & $60(49 ; 71)$ & $65(56.5 ; 71.5)$ & 0.056 \\
\hline Sex, female & $54(50 \%)$ & $61(63 \%)$ & 0.090 \\
\hline Smokers & $33(31 \%)$ & $18(19 \%)$ & 0.052 \\
\hline Smoking, pack/yearł & $20(10 ; 30)$ & $20(20 ; 22.5)$ & 0.920 \\
\hline Drinkers§ & $8(7 \%)$ & $13(13 \%)$ & 0.249 \\
\hline Alcohol, gf & $37(30.5 ; 77.5)$ & $45(35 ; 77)$ & 0.645 \\
\hline $\mathrm{BMI}, \mathrm{kg} / \mathrm{m}^{2}$ & $42.7(38.2 ; 48.8)$ & $42.9(38.1 ; 47.6)$ & 0.604 \\
\hline Neck circumference, cm & $45(41 ; 48)$ & $44(42 ; 47)$ & 0.578 \\
\hline ESS & $10.6(5.19)$ & $11.4(4.96)$ & 0.348 \\
\hline FOSQ & $73.3(21.7)$ & $74.8(21.1)$ & 0.607 \\
\hline SF36-Physical & $34.7(28.5 ; 44.8)$ & $36.7(27.7 ; 45.3)$ & 0.786 \\
\hline SF36-Mental & $45.8(31.6 ; 50.1)$ & $45(32.7 ; 53.2)$ & 0.933 \\
\hline VAWS & $48(30.8 ; 66.6)$ & $50(37.5 ; 58.3)$ & 0.784 \\
\hline Dyspnoea MRC scale $\geq 2$ & $54(54 \%)$ & $61(63 \%)$ & 0.209 \\
\hline Hypertension & $71(66 \%)$ & $69(71 \%)$ & 0.546 \\
\hline Antihypertensive drugs $\ddagger$ & $2(1 ; 2)$ & $2(1 ; 2)$ & 0.532 \\
\hline Systolic BP, mm Hg & $138(130 ; 145)$ & $140(130 ; 150)$ & 0.765 \\
\hline Diastolic BP, mm Hg & $80(70 ; 90)$ & $80(70 ; 90)$ & 0.336 \\
\hline Diabetes & $36(34 \%)$ & $40(41 \%)$ & 0.311 \\
\hline Antidiabetic medications & $34(32 \%)$ & $39(40 \%)$ & 0.243 \\
\hline Dyslipidaemia & $43(40 \%)$ & $47(48 \%)$ & 0.260 \\
\hline Treatment of dyslipidaemia & $37(35 \%)$ & $39(40 \%)$ & 0.469 \\
\hline Stroke & $10(9 \%)$ & $6(6 \%)$ & 0.445 \\
\hline Ischaemic heart disease & $10(9 \%)$ & $8(8 \%)$ & 0.999 \\
\hline Arrhythmia & $6(6 \%)$ & $11(11 \%)$ & 0.204 \\
\hline Chronic heart failure & $13(12 \%)$ & $17(18 \%)$ & 0.325 \\
\hline Leg arteriopathy & $5(5 \%)$ & $5(5 \%)$ & 0.999 \\
\hline Pulmonary hypertension & $9(8 \%)$ & $8(8 \%)$ & 0.999 \\
\hline At least one CVM & $35(33 \%)$ & $33(34 \%)$ & 0.882 \\
\hline CVM & $0(0 ; 1)$ & $0(0 ; 1)$ & 0.575 \\
\hline $\mathrm{pH}$ & $7.40(7.38 ; 7.43)$ & $7.40(7.38 ; 7.42)$ & 0.440 \\
\hline $\mathrm{PaO}_{2}, \mathrm{~mm} \mathrm{Hg}$ & $60(55 ; 67.1)$ & $61(56.7 ; 67)$ & 0.787 \\
\hline $\mathrm{PaCO}_{2}, \mathrm{~mm} \mathrm{Hg}$ & $49(47 ; 52)$ & $51(48 ; 54)$ & 0.300 \\
\hline Bicarbonate, $\mathrm{mmol} / \mathrm{L}$ & $29.5(28 ; 32)$ & $29.8(27.8 ; 31.4)$ & 0.693 \\
\hline $\mathrm{FEV}_{1}$ in $\%$ of predicted & $77(64 ; 90)$ & $77(67.3 ; 88.5)$ & 0.728 \\
\hline FVC in $\%$ of predicted & $82.4(20.8)$ & $77.1(20.4)$ & 0.069 \\
\hline 6-MWD in metres & $372.5(283 ; 448.5)$ & $378(133.4 ; 450)$ & 0.770 \\
\hline \multicolumn{4}{|l|}{$\begin{array}{l}\text { Polysomnographic } \\
\text { parameters }\end{array}$} \\
\hline TST, hours & $5.35(1.37)$ & $5.2(1.23)$ & 0.519 \\
\hline Sleep efficiency & $72.9(59.7 ; 85.3)$ & $72.2(61 ; 84.9)$ & 0.920 \\
\hline Non-REM 1 and 2, \% & $85(74.6 ; 91.5)$ & $85.4(73 ; 92.2)$ & 0.676 \\
\hline Non-REM 3, \% & $6(6 ; 13.4)$ & $3.8(0 ; 16.2)$ & 0.342 \\
\hline REM sleep, \% & $7(3.3 ; 14)$ & $9.18(3.1 ; 14.3)$ & 0.776 \\
\hline Arousal index & $58.5(31.7 ; 85)$ & $56.5(32 ; 75.5)$ & 0.565 \\
\hline $\mathrm{AHI}$ & $68.2(41.6 ; 92.4)$ & $68.7(48.5 ; 97.1)$ & 0.311 \\
\hline ODI & $72.9(39 ; 98.2)$ & $68.8(44 ; 94)$ & 0.700 \\
\hline Mean $\mathrm{SpO}_{2}$ during sleep & $86(81 ; 90)$ & $85(82 ; 88)$ & 0.284 \\
\hline TST with $\mathrm{SpO}_{2}<90 \%, \%$ & $75(48.7 ; 94.2)$ & $79(51.8 ; 95.8)$ & 0.611 \\
\hline Oxygen therapy** & $29(27 \%)$ & $21(22 \%)$ & 0.417 \\
\hline
\end{tabular}

Table 1 Continued

\begin{tabular}{|c|c|c|c|}
\hline & $\begin{array}{l}\text { CPAP } \\
n=107 \\
n(\%) \text { or mean (SD) or } \\
\text { median }(25 ; 75 \text { IQR) }\end{array}$ & $\begin{array}{l}\text { NIV } \\
n=97 \\
n(\%) \text { or mean (SD) or } \\
\text { median }(25 ; 75 \text { IQR) }\end{array}$ & $\mathrm{P}$ valuet \\
\hline $\begin{array}{l}\text { Oxygen therapy flow, L/ } \\
\text { min } \neq\end{array}$ & $1.5(1.3 ; 2)$ & $2(1.1 ; 2)$ & 0.519 \\
\hline \multicolumn{4}{|c|}{ 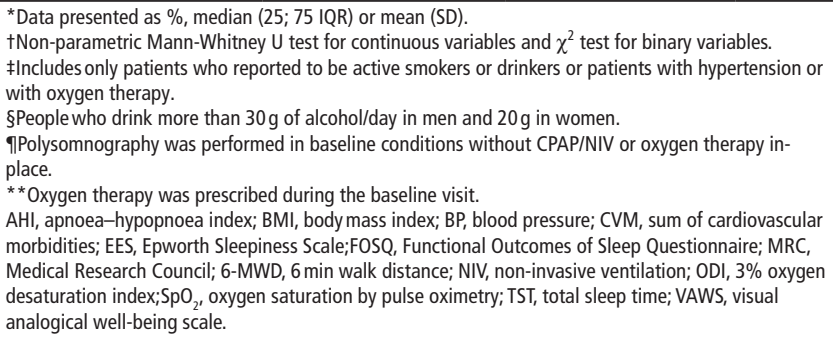 } \\
\hline
\end{tabular}

the CPAP group (an average of $€ 1867.5 /$ year) than in NIV group (an average of $€ 1694.8 /$ year), although not significantly.

\section{Effectiveness assessed in monetary term using Bayesian cost analysis}

The NIV arm had lower mean hospitalisation days/year costs (€484.8 for NIV vs €604.3 for CPAP) (table 3). The lower proportion of patients admitted (35.4\% for NIV vs $35.8 \%$ for CPAP) did not explain this lower cost but rather shorter stays of those hospitalised who were in the NIV arm. As it relates to the other costs, the average cost of patients treated with NIV was higher than CPAP, $€ 2076.0$ versus $€ 1219.1$, respectively. This higher cost was greater than the savings observed from hospitalisation days. Therefore, CPAP is preferred to NIV $(99.5 \%$ probability) given that treatment with CPAP led to sufficiently lower costs to overcome the cost of longer hospital stay (figure 2A).

\section{Effectiveness assessed as hospitalisation days/year using Bayesian cost-effectiveness analysis}

Patients in the NIV arm had lower average days of hospital stay (1.89 days/year) in comparison with CPAP (2.13 days/ year) (table 3). Taking into account this incremental effectiveness, the probability that the number of hospital days with NIV is lower than that of CPAP is $62.2 \%$ (ie, 100\%-37.8\%). The average cost of patients treated with NIV (other cost groups without effectiveness cost) was much higher (€2076.0) than with CPAP (€1219.1) (table 3). NIV was, therefore, more effective, but more expensive (figure $2 \mathrm{~B}$ ). The preferred treatment will depend on how much clinicians, patients and stakeholders are willing to pay to reduce the hospital length of stay.

The cost-effectiveness acceptability curve (figure 2C) shows that treatment with NIV was not preferred for a willingness to pay per one hospital day less than $€ 3433$. The willingness to pay per one hospital day should include its cost and the cost derived from to prevent a hospitalisation day. Taking into account that the cost estimated for a hospitalisation day was between $€ 340$ and $€ 516$ (depending on the hospital), we can conclude that the willingness to pay per one hospitalisation day does not reach the threshold, so we conclude that CPAP was the preferred treatment.

\section{Sensitivity analysis for early abandons}

Three scenarios were explored in regards to treatment abandons and the results were consistent in favour of CPAP treatment (see online supplement). 
Table 2 Raw data of effectiveness and costs*

\begin{tabular}{|c|c|c|c|c|}
\hline & $\begin{array}{l}\text { CPAP } \\
n=107 \\
n(\%) \text { or mean (SD) }\end{array}$ & $\begin{array}{l}\text { NIV } \\
n=97 \\
n(\%) \text { or mean }(S D)\end{array}$ & $\begin{array}{l}\text { Total } \\
\mathrm{n}=204 \\
\mathrm{n}(\%) \text { or mean (SD) }\end{array}$ & $P$ valuet \\
\hline \multicolumn{5}{|l|}{ Effectiveness } \\
\hline Patients with admission & $38(35.5 \%)$ & $34(35.1 \%)$ & $72(35.3 \%)$ & 0.945 \\
\hline Follow-up hospitalisation days $\ddagger$ & $16.0(20.6)$ & $14.0(19.9)$ & $15.0(20.1)$ & 0.415 \\
\hline Hospitalisation days/year & $5.2(6.3)$ & $4.7(6.7)$ & $5.0(6.5)$ & 0.332 \\
\hline \multicolumn{5}{|l|}{ Effectiveness cost } \\
\hline Follow-up hospitalisation days cost, $€ \neq$ & $5723.9(6925.3)$ & $5042.1(6713.3)$ & $5401.9(6786.6)$ & 0.415 \\
\hline Hospitalisation days cost/year, $€ \neq$ & $1867.5(2120.6)$ & $1694.8(2276.7)$ & $1786.0(2181.8)$ & 0.321 \\
\hline Other resources costs/year & & & & 0.578 \\
\hline ICU days and emergency department visits, $€$ & $202.5(574.3)$ & $151.6(488.5)$ & $178.3(534.5)$ & 0.329 \\
\hline Short/long clinic visits, $€$ & $65.2(10.5)$ & $69.1(43.3)$ & $67.0(30.8)$ & 0.000 \\
\hline NIV daytime adjustment and tests, $€$ & $451.8(53.2)$ & $670.3(1420.7)$ & $555.7(983.9)$ & 0.000 \\
\hline Medication, $€$ & $177.2(218.9)$ & $186.0(207.1)$ & $181.4(212.9)$ & 0.336 \\
\hline Home care for PAP therapy, $€$ & $338.3(174.0)$ & $1138.2(823.3)$ & $718.7(704.7)$ & 0.000 \\
\hline Total other resources, $€$ & $1235.0(629.3)$ & $2215.2(2322.7)$ & $1701.1(1731.7)$ & 0.000 \\
\hline
\end{tabular}

*Data per patient, except the percentage of patients with admission that is related to all population.

tNon-parametric Mann-Whitney $\mathrm{U}$ test for continuous variables and $\chi^{2}$ test for binary variables.

łIncludes only patients who reported to be hospitalised at least once.

NIV, non-invasive ventilation.

\section{High and low adherence subgroups: NIV versus CPAP}

High and low adherence subgroups had cost-effectiveness results similar to the entire cohort (see online supplement). The high adherence subgroup had a better cost-effectiveness relationship than low adherence subgroup, regardless of whether the patient was being treated with NIV or CPAP.

\section{Cost-effectiveness analysis with FOSQ}

CPAP was the preferred treatment similar to that was observed in the main cost-effectiveness analysis (see online supplement).

\section{DISCUSSION}

This study is the only reported analysis to date showing the comparative long-term cost-effectiveness between NIV and CPAP in ambulatory patients with stable OHS with severe OSA. The main results can be summarised as follows: (1) the effectiveness (hospitalisation days) was slightly better with NIV but without reaching a statistically significant difference; (2) the costs (without hospitalisation days costs) was much higher with $\mathrm{NIV}$; (3) the cost-effectiveness relationship was favourable to CPAP because the lower cost of CPAP sufficiently compensated its higher cost of hospitalisation days, even for willingness to pay for a day of hospitalisation greater than the mean cost of this service in the centres analysed; (4) similar results were found in the high and low NIV and CPAP adherence subgroups.

There is limited information on the cost of OHS and there are no cost-effectiveness studies. A retrospective Danish study assessed the direct and indirect costs of OHS using a top-to-bottom methodology. ${ }^{8}$ The direct cost was close to four times higher than control subjects (citizens without a diagnosis of OHS paired by age, sex and socioeconomic status) and the sum of direct and indirect costs were more than seven times of that in controls. The influence of CPAP or NIV on the total cost was not evaluated. The direct cost of OHS was $€ 6843$ year-patient. ${ }^{8}$ However, in our study, the mean

Table 3 Bayesian cost-effectiveness estimation*

\begin{tabular}{|c|c|c|c|c|}
\hline & $\begin{array}{l}\text { CPAP } \\
\mathrm{n}=107 \\
\text { Mean (SD) } \\
(95 \% \mathrm{Cl})\end{array}$ & $\begin{array}{l}\text { NIV } \\
n=97 \\
\text { Mean (SD) } \\
(95 \% \mathrm{Cl})\end{array}$ & $\begin{array}{l}\text { NIV-CPAP } \\
\text { Mean (SD) } \\
(95 \% \mathrm{Cl})\end{array}$ & Prob (NIV-CPAP>0) $(\%)$ \\
\hline Probability of hospitalisation & $\begin{array}{l}35.8 \%(4.6) \\
(27.1 \text { to } 44.9)\end{array}$ & $\begin{array}{l}35.4 \%(4.8) \\
\text { (26.3 to } 45.0)\end{array}$ & $\begin{array}{l}-0.4 \%(6.6) \\
(-13.3 \text { to } 12.6)\end{array}$ & 47.4 \\
\hline Effectiveness (hospitalisation days/year) & $\begin{array}{l}2.13(0.73) \\
\text { (1.17 to } 3.91)\end{array}$ & $\begin{array}{l}1.89 \text { (0.78) } \\
\text { (0.95 to } 3.82)\end{array}$ & $\begin{array}{l}-0.24(1.07) \\
(-2.30 \text { to } 1.94)\end{array}$ & 37.8 \\
\hline Effectiveness (hospitalisation days/year cost), $€$ & $\begin{array}{l}604.3(162.9) \\
\text { (364.0 to } 990.9)\end{array}$ & $\begin{array}{l}484.8(147.3) \\
\text { (277.1 to } 836.9)\end{array}$ & $\begin{array}{l}-119.5(219.6) \\
(-563.5 \text { to } 308.8)\end{array}$ & 26.9 \\
\hline Other costs/year, $€$ & $\begin{array}{l}1219.1 \text { (52.3) } \\
\text { (1125.0 to } 1331.0)\end{array}$ & $\begin{array}{l}2076.0 \text { (91.6) } \\
\text { (1907.0 to 2073.0) }\end{array}$ & $\begin{array}{l}857.6(105.5) \\
(654.9 \text { to } 1070.0)\end{array}$ & 100.0 \\
\hline Total costs/year, $€$ & $\begin{array}{l}1823.0(179.4) \\
(1540.0 \text { to } 2237.0)\end{array}$ & $\begin{array}{l}2561.0(181.7) \\
\text { (2266.0 to } 2969.0)\end{array}$ & $\begin{array}{l}738.1(255.2) \\
\text { (231.9 to } 1238.0)\end{array}$ & 99.5 \\
\hline
\end{tabular}

*Data per patient, except 'probability of hospitalisation' that is the Bayesian estimation of the individual probability of being hospitalised. NIV, non-invasive ventilation; Prob, probability. 


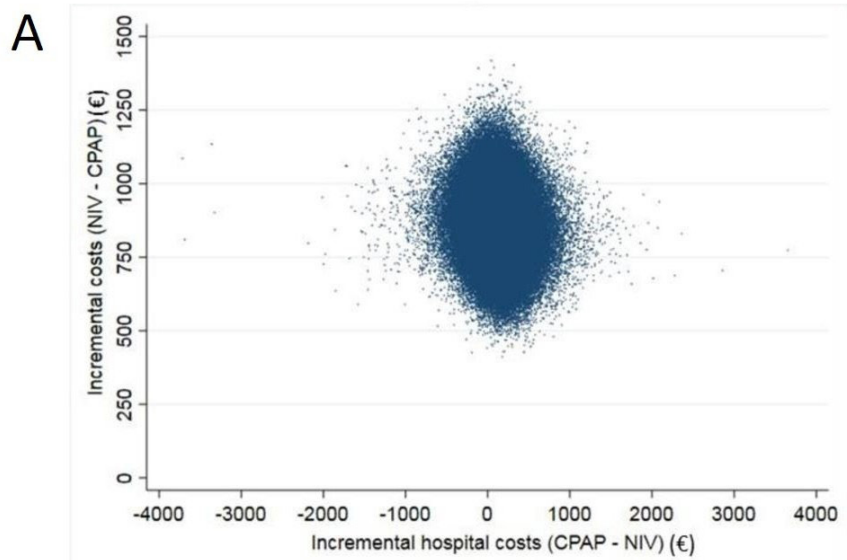

B

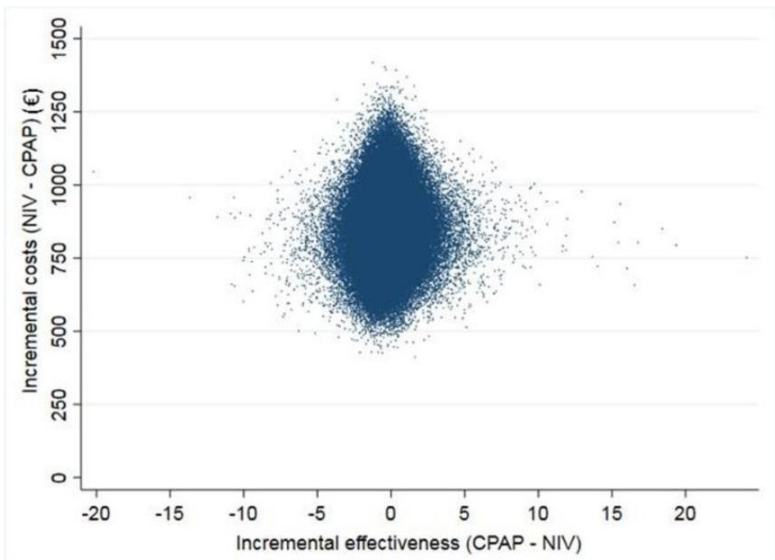

C

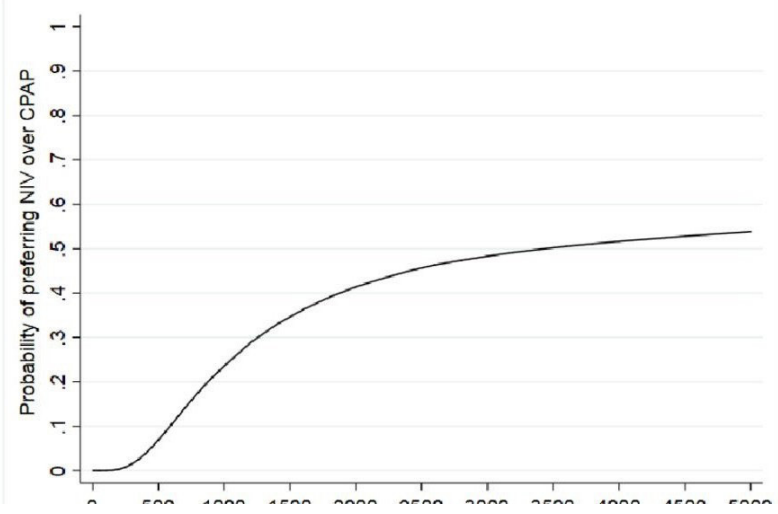

Figure 2 (A) Cost-effectiveness plane converting effectiveness to monetary term. The probabilistic Bayesian analysis indicated that CPAP was preferable. Although non-invasive ventilation (NIV) saved hospital cost, NIV was much more expensive in terms of the remaining services. (B) Cost-effectiveness plane assessing the effectiveness as hospitalisation days/year. The probabilistic Bayesian analysis indicated that CPAP was preferable. Although NIV reduced hospitalisation days, NIV was much more expensive. (C) Cost-effectiveness acceptability curve assessing the effectiveness as hospitalisation days/year. The probabilities of preference for NIV by different levels of willingness to pay for one extra day of hospitalisation. The advisable willingness to pay limit corresponds to the $50 \%$ cost-effectiveness probability indicating that in some situations, NIV is preferred.

direct costs year-patient using the Bayesian approach was $€ 1823.0$ for CPAP and $€ 2561.0$ for NIV (table 3), observing a ratio of 1:1.4 which increases to a ratio $1: 1.7$ if hospital costs are not included. In contrast to the Danish study, ${ }^{8}$ the methodology of the present trial included real cost from a population of patients with OHS during 3 years with minimal imputation and without disaggregated costs typical of a top-to-bottom approach. Moreover, Denmark has close to two times higher international gross domestic product than Spain, and therefore, much higher cost may be expected in such countries. ${ }^{39}$

A few observational and registry studies have shown increased healthcare resource utilisation in patients with untreated OHS compared with controls, ${ }^{4} 811$ and reduction in healthcare resource utilisation after initiating nocturnal PAP therapy. ${ }^{4}$ In the present analysis, the overall duration and frequency of hospitalisation was lower than a prior retrospective study published in $2001^{4}$ (2.5 days/year after 2 years of follow-up vs 2.13 days/year in our CPAP group and 1.89 days/year in our NIV group after a mean of 3 years of follow-up) (table 3 ). The reason for this discrepancy may be due to different follow-up periods, time of study performance with different ventilators, mode of ventilation and protocols, among others.

Patients treated with CPAP had slightly higher hospitalisation days but similar number of hospital admissions than those treated with NIV. There was significant variability in the duration of hospital days and a few patients treated with CPAP had long admissions. Despite this unfavourable result for CPAP, the advantage in cost (excluding hospitalisation days/year cost) was $€ 857.6$ per year-patient (table 3). The cost-effectiveness relationship was favourable for CPAP. Even when we assessed the effectiveness (hospitalisation days) as a monetary burden, the final saving from CPAP was $€ 738.1$ per year-patient, reinforcing the favourable cost-effectiveness relationship. The cost-effectiveness advantage of CPAP was mainly driven by its lower home care cost.

The subgroup with higher adherence had lower hospital resource utilisation and mortality than the subgroup with lower adherence. ${ }^{26}$ Consequently, the cost of PAP (both CPAP and NIV) was lower in the high adherence subgroup (online supplementary tables S5 and S6). However, the cost-effectiveness relationship (considering the effectiveness in hospitalisation days or in monetary term) was also favourable for CPAP in both high and low adherence subgroups, indicating that the observed costeffectiveness results are consistent.

\section{Limitations}

Hospitalisation days for any cause was selected as the primary outcome, as an indicator of healthcare resource utilisation, because when the trial was designed in 2007, the only longterm outcome existing in the literature was hospitalisation days/year. Patients with OHS have many comorbidities and PAP therapy could possibly improve some of these comorbidities leading to reduced hospitalisation. HRQL variables (FOSQ, SF36 and VAWS) were also collected but they had a high proportion of missing data (above 25\%), so they were discarded as primary outcome for the main cost-effectiveness analysis. A secondary analysis using FOSQ showed similar conclusions to that obtained by the main analysis (see online supplement).

The study was designed to show inequality between interventions under the assumption of a change in the mean differences for the primary outcome -0.5 days/year. The mean difference for hospitalisation days was -0.24 days/year. However, -0.5 days/year is included in the CI of hospitalisation days $(-2.30$ to 1.94$)$. This inaccuracy leads to a certain degree of uncertainty in the inequality affirmation. Nevertheless, considering all of the outcomes, ${ }^{26}$ our interpretation of the data was that both treatment groups seem to have similar 
long-term effectiveness. Besides, the favourable cost analysis of CPAP means that although NIV may have a similar or slightly higher effectiveness, CPAP is preferable given its lower cost.

Our cost estimate could be biased because of the post hoc nature of the analysis. Since the intervention groups are well balanced and we have most of the outcomes assessed in cost units, these biases should affect both arms similarly. We believe that the differential costs (and its longitudinal changes) between CPAP and NIV are accurately included in the analysis. Another limitation is that our study calculated the withintrial costs which may vary in real-life clinical practice. Our study was performed exclusively in Spain and cost burdens are logically different in other countries/communities. Since the cost-effectiveness results were quite robust, we do not expect a change in the result in other countries, although the difference in cost between CPAP and NIV may vary according to the international gross domestic product of each nation. Our cohort was limited to patients with OHS who also had concomitant severe OSA. However, the great majority of patients with OHS have severe OSA, ${ }^{3}$ therefore increasing the generalisability of our findings.

In summary, the present cost-effectiveness analysis reinforces the conclusion that CPAP should be considered the first line of treatment in ambulatory patients with severe OSA, but a case-by-case assessment is also recommended because the cost-effectiveness advantage may be counterbalanced if patients treated with CPAP have high rates of hospitalisation or hospital resource utilisation.

\section{Author affiliations \\ ${ }^{1}$ Respiratory Department, San Pedro de Alcantara Hospital, Caceres, Spain \\ ${ }_{2}^{2}$ CIBER de enfermedades respiratorias (CIBERES), Madrid, Spain \\ ${ }^{3}$ Institut de Recerca Biomédica de LLeida (IRBLLEIDA), Lleida, Spain \\ ${ }^{4}$ Instituto Universitario delnvestigación Biosanitaria de Extremadura (INUBE), Romero, Auxiliadora \\ ${ }^{5}$ Medicine/Pulmonary and Critical Care, University of Chicago, Chicago, Illinois, USA \\ ${ }^{6}$ Respiratory Department, Virgen del Rocio University Hospital, Plasencia, Spain \\ ${ }^{7}$ nidad Médico-Quirúrgica de Enfermedades Respiratorias, Instituto de Biomedicina de Sevilla (IBiS), Hospital Universitario Virgen del Rocío/Universidad de Sevilla, Sevilla, Spain \\ ${ }^{8}$ Respiratory Department, Universitario de Burgos Hospital, Burgos, Spain \\ ${ }^{9}$ Pulmonology, IIS Fundación Jiménez Díaz, Madrid, Spain \\ ${ }^{10}$ Respiratory Department, Valdecilla Hospital, Santander, Spain \\ ${ }^{11}$ Respiratory Department, Gregorio Marañon Hospital, Madrid, Spain \\ ${ }^{12}$ Respiratory Department, Miguel Servet Hospital, Zaragoza, Spain \\ ${ }^{13}$ Respiratory Department, Valld'Hebron Hospital, Barcelona, Spain \\ ${ }^{14}$ Respiratory Department, Doce de Octubre Hospital, Madrid, Spain \\ ${ }^{15}$ Respiratory Department, San Juan Hospital, Alicante, Spain \\ ${ }^{16}$ Respiratory Department, La Paz Hospital, Madrid, Spain \\ ${ }^{17}$ Nursing Department, Extremadura University, Cáceres, Spain \\ ${ }^{18}$ Department of Quantitative Methods, University of Las Palmas de Gran Canaria, Las Palmas, Spain}

Twitter Javier Barca @javierbd22@gmail.com and Miguel Angel Negrín@ manegrinhdez

Acknowledgements We are indebted to Verónica Rodríguez for her assistance in the translation of the manuscript and to Vanessa Iglesias for her technical assistance.

Contributors Substantial contributions to study conception and design, acquisition of data, or analysis and interpretation of data: JFM, M-ÁS-Q, FJGdT, IB, F-JV-P, MAN, MM-E, FB, AR, CC-E, EO-C, MLA-Á, TG-G, MG, SL-M, JMM, OR, TD-C, EC, CE, BM, $J C, I U, J B, E O, N G-M$, MFT, M-ÁM-M, EO-C, DLP, SJC, BG, MP, OR, SM, MAR, EA, $J M-M, C S$, JNS-C, NBNS, JS-G, RG, AS-R and MB. Drafting the article or revising the article critically for important intellectual content: JFM, BM, IB, FJGdT, MÁS-Q, AR, CC-E, EO, MLA-Á, MFT, MG, SL-M, JMM, SM, TD-C, EC, CE, F-JV-P, MAN, MM-E, FB and JC. Performing of the version to be published: JFM, BM, IB, F-JV-P, MAN and JC. Agreement to be accountable for all aspects of the work in ensuring that questions related to the accuracy or integrity of any part of the work are appropriately investigated and resolved: JFM. JFM has full access to all data from the study and takes responsibility for the integrity of the data, the accuracy of the data analysis and for the decision to submit for publication.
Funding Instituto de Salud Carlos III (Fondo de Investigaciones Sanitarias, Ministerio de Sanidad y Consumo) PI050402, Spanish Respiratory Foundation 2005 (FEPAR) and Air Liquide Spain.

Disclaimer The sponsors and funders of the study had no involvement or any influence in study design; in the collection, analysis and interpretation of data; in the writing of the manuscript; and in the decision to submit the manuscript for publication.

Competing interests None declared.

Patient consent for publication Obtained.

Ethics approval The study was approved by the ethics committees of the 16 centres.

Provenance and peer review Not commissioned; externally peer reviewed.

Data availability statement All data relevant to the study are included in the article or uploaded as online supplementary information.

\section{ORCID iDs}

Juan F Masa http://orcid.org/0000-0002-2353-5353

Babak Mokhlesi http://orcid.org/0000-0001-8135-5433

Iván Benitez http://orcid.org/0000-0002-3558-5948

Francisco Javier Gómez de Terreros Caro http://orcid.org/0000-0001-8294-4918

M-Ángeles Sánchez-Quiroga http://orcid.org/0000-0002-7220-6142

Auxiliadora Romero http://orcid.org/0000-0002-6222-9172

Candela Caballero http://orcid.org/0000-0002-6428-0027

Maria Luz Alonso-Álvarez http://orcid.org/0000-0002-7757-0795

Estrella Ordax-Carbajo http://orcid.org/0000-0002-6647-3068

Teresa Gómez-García http://orcid.org/0000-0003-1373-361X

Mónica González http://orcid.org/0000-0003-1516-0181

Soledad López-Martín http://orcid.org/0000-0002-7667-5499

Jose M Marin http://orcid.org/0000-0001-9096-2294

Sergi Martí http://orcid.org/0000-0003-3554-7172

Trinidad Díaz-Cambriles http://orcid.org/0000-0002-1924-9899

Eusebi Chiner http://orcid.org/0000-0003-3374-4623

Carlos Egea http://orcid.org/0000-0002-7618-7444

Javier Barca http://orcid.org/0000-0002-3532-8255

Francisco-José Vázquez-Polo http://orcid.org/0000-0002-0632-6138

Miguel Angel Negrín http://orcid.org/0000-0002-7074-6268

María Martel-Escobar http://orcid.org/0000-0002-7013-4747

Ferran Barbé http://orcid.org/0000-0002-2340-8928

Jaime Corral-Peñafiel http://orcid.org/0000-0003-0353-0114

\section{REFERENCES}

1 Mokhlesi B, Kryger MH, Grunstein RR. Assessment and management of patients with obesity hypoventilation syndrome. Proc Am Thorac Soc 2008;5:218-25.

2 Kessler R, Chaouat A, Schinkewitch P, et al. The obesity-hypoventilation syndrome revisited: a prospective study of 34 consecutive cases. Chest 2001;120:369-76.

3 Masa JF, Corral J, Alonso ML, et al. Efficacy of different treatment alternatives for obesity hypoventilation syndrome. Pickwick study. Am J Respir Crit Care Med 2015;192:86-95.

4 Castro-Añón O, Pérez de Llano LA, De la Fuente Sánchez S, et al. Obesityhypoventilation syndrome: increased risk of death over sleep apnea syndrome. PLOS One 2015;10:e0117808.

5 Basoglu OK, Tasbakan MS. Comparison of clinical characteristics in patients with obesity hypoventilation syndrome and obese obstructive sleep apnea syndrome: a case-control study. Clin Respir J 2014;8:167-74.

6 Priou P, Hamel J-F, Person C, et al. Long-term outcome of noninvasive positive pressure ventilation for obesity hypoventilation syndrome. Chest 2010;138:84-90.

7 Berg G, Delaive K, Manfreda J, et al. The use of health-care resources in obesityhypoventilation syndrome. Chest 2001;120:377-83.

8 Jennum P, Kjellberg J. Health, social and economical consequences of sleep-disordered breathing: a controlled national study. Thorax 2011;66:560-6.

9 Pérez de Llano LA, Golpe R, Ortiz Piquer M, et al. Short-term and long-term effects of nasal intermittent positive pressure ventilation in patients with obesityhypoventilation syndrome. Chest 2005;128:587-94.

10 Ojeda Castillejo E, de Lucas Ramos P, Resano Barrios P, et al. Noninvasive mechanical ventilation in patients with obesity hypoventilation syndrome: long-term outcome and prognostic factors. Arch Bronconeumol.

11 Nowbar S, Burkart KM, Gonzales R, et al. Obesity-associated hypoventilation in hospitalized patients: prevalence, effects, and outcome. Am J Med 2004;116:1-7.

12 Zwillich CW, Sutton FD, Pierson DJ, et al. Decreased hypoxic ventilatory drive in the obesity-hypoventilation syndrome. Am J Med 1975;59:343-8.

13 MacGregor M, Block AJ, Ball WC. Topics in clinical medicine: serious complications and sudden death in the Pickwickian syndrome. Hopkins Med J 1970;126:279-95.

14 Miller A, Granada M. In-hospital mortality in the Pickwickian syndrome. Am J Med 1974;56:144-50. 
15 Budweiser S, Riedl SG, Jörres RA, et al. Mortality and prognostic factors in patients with obesity-hypoventilation syndrome undergoing noninvasive ventilation. J Intern Med 2007;261:375-83.

16 de Lucas-Ramos P, de Miguel-Díez J, Santacruz-Siminiani A, et al. Benefits at 1 year of nocturnal intermittent positive pressure ventilation in patients with obesityhypoventilation syndrome. Respir Med 2004;98:961-7.

17 Borel J-C, Burel B, Tamisier R, et al. Comorbidities and mortality in hypercapnic obese under domiciliary noninvasive ventilation. PLoS One 2013;8:e52006.

18 Janssens JP, Derivaz S, Breitenstein E, et al. Changing patterns in long-term noninvasive ventilation: a 7-year prospective study in the Geneva Lake area. Chest 2003;123:67-79.

19 Berger KI, Ayappa I, Chatr-amontri B, et al. Obesity hypoventilation syndrome as a spectrum of respiratory disturbances during sleep. Chest 2001;120:1231-8.

20 Heinemann F, Budweiser S, Dobroschke J, et al. Non-invasive positive pressure ventilation improves lung volumes in the obesity hypoventilation syndrome. Respir Med 2007;101:1229-35.

21 Windisch W. Quality of Life in Home Mechanical Ventilation Study Group. Impact of home mechanical ventilation on health-related quality of life. Eur Respir $J$ 2008;32:1328-36.

22 Borel JC, Tamisier R, Gonzalez-Bermejo J, et al. Noninvasive ventilation in mild obesity hypoventilation syndrome: a randomized controlled trial. Chest 2012;141:692-702.

23 Masa JF, Corral J, Caballero C, et al. Non-invasive ventilation in obesity hypoventilation syndrome without severe obstructive sleep apnoea. Thorax 2016:71:899-906.

24 Piper AJ, Wang D, Yee BJ, et al. Randomised trial of CPAP vs bilevel support in the treatment of obesity hypoventilation syndrome without severe nocturnal desaturation. Thorax 2008;63:395-401.

25 Howard ME, Piper AJ, Stevens B, et al. A randomised controlled trial of CPAP versus non-invasive ventilation for initial treatment of obesity hypoventilation syndrome. Thorax 2017;72:437-44

26 Masa JF, Mokhlesi B, Benítez I, et al. Long-term clinical effectiveness of continuous positive airway pressure therapy versus non-invasive ventilation therapy in patients with obesity hypoventilation syndrome: a multicentre, open-label, randomised controlled trial. Lancet 2019:32978-7.
27 Masa JF, Corral J, Romero A, et al. Protective cardiovascular effect of sleep apnea severity in obesity hypoventilation syndrome. Chest 2016;150:68-79.

28 López-Jiménez MJ, Masa JF, Corral J, et al. Mid- and long-term efficacy of non-invasive ventilation in obesity hypoventilation syndrome: the Pickwick's study. Archivos de Bronconeumología 2016;52:158-65.

29 Corral J, Mogollon MV, Sánchez-Quiroga M-Ángeles, et al. Echocardiographic changes with non-invasive ventilation and CPAP in obesity hypoventilation syndrome. Thorax 2018;73:361-8.

30 Masa JF, Corral J, Romero A, et al. The effect of supplemental oxygen in obesity hypoventilation syndrome. JCSM 2016;12:1379-88.

31 Chobanian AV, Bakris GL, Black HR, et al. Joint National Committee on Prevention, Detection, Evaluation, and Treatment of High Blood Pressure. National Heart, Lung, and Blood Institute; National High Blood Pressure Education Program Coordinating Committee. Seventh report of the Joint National Committee on Prevention, Detection, Evaluation, and Treatment of High Blood Pressure. Hypertension 2003;42:1206-52.

32 García-Río F, Calle M, Burgos F. Spanish Society of Pulmonology and Thoracic Surgery (SEPAR). Spirometry. Arch Bronconeumol 2013;49:388-401.

33 ATS Committee on proficiency standards for clinical pulmonary function laboratories. ATS statement: guidelines for the six-minute walk test. Am J Respir Crit Care Med 2002;166:111-7.

34 Masa JF, Jiménez A, Durán J, et al. Alternative methods of titrating continuous positive airway pressure: a large multicenter study. Am J Respir Crit Care Med 2004:170:1218-24.

35 Masa JF, Jiménez A, Durán J, et al. Spanish group of breathing sleep disorders. visual analogical well-being scale for sleep apnea patients: validity and responsiveness: a test for clinical practice. Sleep Breath 2011;15:549-59.

36 Moreno E, Vázquez-Polo FJ, Negrín MA. Bayesian cost-effectiveness analysis of medical treatments. Chapman \& Hall. Boca Raton, FL: CRC Press, 2019.

37 Berger J. The case for objective Bayesian analysis. Bayesian Anal 2006;1:385-402.

38 Baio G. Bayesian models for cost-effectiveness analysis in the presence of structural zero costs. Stat Med 2014;33:1900-13.

39 StatisticsTimes. List of countries by projected GDP per capita, 2019. Available: http:// statisticstimes.com/economy/countries-by-projected-gdp-capita.php 
(c) 2020 Author(s) (or their employer(s)) 2020. No commercial re-use. See rights and permissions. Published by BMJ. 